Article

\title{
Grave Reminders: Grief and Vulnerability in the Anthropocene ${ }^{\dagger}$
}

\author{
Lisa H. Sideris \\ Department of Religious Studies, Indiana University, Bloomington, IN 47405, USA; lsideris@indiana.edu \\ † This essay is dedicated to students in my Spring 2020 seminar on "Extinction" at Indiana University. \\ Thank you for reading and discussing sometimes painful material on species death and environmental grief \\ with me (until a pandemic, whose origins almost certainly lie in humans' destruction of the natural world, \\ isolated us from one another). I fully acknowledge that my generation has failed you.
}

Received: 11 May 2020; Accepted: 9 June 2020; Published: 16 June 2020

check for

Abstract: This essay builds upon recent work in the environmental humanities, and that of various writers and journalists, on the emerging topic of environmental grief and mourning. I consider a spectrum of responses to Anthropocene-era crises like climate change and extinction, with particular emphasis on how we are oriented toward the past and the future. These perspectives range from positions that explicitly reject grief and vulnerability, to voices urging us to embrace grief as part of an essential moral and spiritual environmental practice. At one end of the spectrum, we find articulations of what I call climate humanism, a style of response focused on defending and perpetuating human civilization in the midst of environmental crisis, but with little or no explicit concern for the broader web of living and dying beings. For climate humanists, to grieve for the past and its mistakes is to halt progressive, optimistic movement into the future. At the other end of the spectrum, we find scholars and writers who take profound grief, and sustained reflection on death and loss, as the starting point for genuine, transformative change and the possibility of hope. Drawing on this range of responses to environmental threats and losses, I endorse narratives that ground themselves in the past, in all its surprises and mistakes, as a vital resource and repository for moving hopefully and purposefully into the future. Moral, religious, and religious-like dimensions of environmental grief (or its denial) are recurring themes throughout, and many crucial insights are found in scholarship outside of religious studies.

Keywords: grief and mourning; hope; Anthropocene; climate change; extinction; climate humanism

\begin{abstract}
"We are witnesses, and as we probe the ethics of relation and substance, perhaps working our way toward the uncertainty of a quantum god, we may yet engage with the wider gravity of keeping faith in the midst of devastation"-Deborah Bird Rose, Wild Dog Dreaming. (Rose 2011, p. 107)
\end{abstract}

I am not an optimist by disposition. For precisely that reason, I have often sifted through, and mostly found wanting, many narratives of so-called hope in the so-called Anthropocene. ${ }^{1}$ This essay constitutes a meditation on-perhaps more than an argument for-the power and moral significance of grief and mourning in orienting us properly toward an uncertain and perilous future. I explore a spectrum of responses to the current environmental crisis, with particular attention to issues

1 In much of what follows, I treat climate change and the current extinction crisis as a shorthand for the Anthropocene concept that humans have become a force reshaping the planet on a geological scale. My focus here is less on the implicitly religious nature of the Anthropocene itself than on grief and mourning as responses to it. For a discussion of the former and of the problematic nature of the Anthropocene concept itself, see (Sideris 2016). 
of climate change and species extinction. Some of these responses adopt-to varying degrees-a kind of defensive humanist posture that privileges human civilization and seeks to insulate it, to fortify it, against the shocks of climate change and related disasters. Wittingly or not, this defensive stance implicitly renders Earth and nonhuman beings as something less than animate and living, and in doing so, disavows nonhuman nature as truly mournable. Other voices invite us into grief and vulnerability as potentially transformative, contemplative states that reconnect us with human and nonhuman others, and with our own painful history of losses and failures. My own sensibilities incline me toward the latter set of responses, and their potential to humanize us in the midst of crisis. These voices, I believe, contain clues about how to remain upright and forward-facing, how to carry on in the most basic sense of putting one foot in front of the other, when the future is almost unimaginable and the past seems somehow irretrievable, or simply irrelevant to the present situation.

The stories we tell about hope and loss are more important than ever if we aspire to make the "Age of Humans" a little more humane. An unwillingness or inability to mourn for the broader spectrum of life bespeaks a worrisome evasion of responsibility for environmental harms. Building upon existing scholarship in the environmental humanities and the work of contemporary writers and journalists, I affirm practices and perspectives that contain somber yet hopeful messages about the complex ways in which the past can orient us toward the future, in contrast to progressivist narratives urging us to relinquish the past and its missteps. By weaving together various narrative strands, ranging from contemporary stories of climate collapse, political action, and spiritual practice, to longstanding myths about death and loss, I consider the value of consciously attending to death, mourning, and loss as a step toward moral reckoning and meaningful change. ${ }^{2}$ The story of a small Icelandic glacier, and its recent death from climate change, presents an especially compelling resource for reflection on these interlocking themes. But first, we must consider how and why environmental grief often seems strangely muted or suppressed.

\section{Denial and Grievability}

Some of the most important insights regarding environmental hope and grief are currently to be found in nontraditional sources, such as podcasts, blogs, and online news stories. These indicate a somewhat spontaneous upsurge in grief and mourning in the face of climate change, extinction, and the Anthropocene generally. ${ }^{3}$ Climate protests like Extinction Rebellion are beginning to attract attention from academics and journalists alike, and recently some scholars have analyzed the ritual dimensions, and the religious commitments and overtones of these movements (Skrimshire 2019). On the whole, however, scholarship in religious studies and the broader humanities has been somewhat slow to register outpourings of environmental grief and mourning. "Despite the commonality of experiencing negative or emotional responses to environmental degradation," Ashlee Cunsolo notes, "ecological losses do not appear in broader public and academic discourses concerning climate change-as though animal, vegetal, and mineral bodies are somehow constituted to be ungrievable in these broader narratives" (Cunsolo 2017, p. 170). While this situation is changing, some notable gaps in the literature remain. Willis Jenkins observes, for example, that while theologians and religion scholars have addressed nearly every facet of the environmental crisis in recent decades, almost none have paid attention to human-caused extinction, and particularly mass extinction, even though these concepts

2 Throughout this essay, I draw primarily from narratives of the Eurowestern world, with regard both to stories of loss and those with a progressivist future orientation. My critical commentary, therefore, is not intended to encompass all cultures and histories, nor to suggest some homogenized human "we." Many cultures would not recognize Western linear notions of the past, present, and future. However, certain features and experiences of being human-grief, death, hope, and finitude-do have some general relevance as part of the human condition, however they are dealt with across cultures or religions.

3 An internet search for the terms "environmental grief" and "ecological grief" turns up numerous recent sources, including several devoted to the often private grief of climate scientists. The term "ecological grief" warrants a Wikipedia page (https://en.wikipedia.org/wiki/Ecological_grief). 
have permeated human consciousness longer than issues like climate change (Jenkins n.d.). Might there be a denial of death at work?

Currently, humanities scholarship that does address extinction often comes from fields of study adjacent to religious studies, but, as with Anthropocene narratives generally, these stories exhibit implicit or thinly secularized religious overtones. Like discourse on the Anthropocene generally, discussions of extinction, and of the fascinating and troubling efforts to de-extinct species, often entail an outright rejection of tragic or elegiac moods, in favor of upbeat narratives that aggrandize the human species. In Imagining Extinction, Ursula Heise notes the peculiar way in which humans' current impacts on the environment are presented in tones of "awed celebration" and "wide-eyed optimism" at the possibility of a planet reshaped by humans (Heise 2016, p. 206). There is a distinctly "forward-facing" orientation to these narratives, a glorification of humans as creatures who plunge ahead rather than looking over their shoulder at the mistakes of the past. Rather than serve as confirmation of past and present failures, the Anthropocene and associated extinction events are recast as the seeds of a new, exciting, and forward-looking environmentalism. This orientation is apparent, for example, in Diane Ackerman's appraisal of our Anthropocene moment in The Human Age. Ackerman sees humans as having arrived at a critical juncture-a great turning - where the deep past meets a tantalizing future. "Behind us eons of geological history, ahead a mist-laden future, and all around us the wonders and uncertainties of the Human Age." Uncertainties notwithstanding, we are now positioned to take control of that future, she believes, for humans are wonder-workers and dreamsmiths. "What a marvel we have become" (Ackerman 2015, p. 308).

Even Heise, who is skeptical of the mournful, elegiac mode of environmental storytelling, finds this overtly sanguine, future orientation somewhat puzzling. Regarding de-extinction in particular, optimism about its potential to rewrite the story of environmental decline depends on embracing de-extinction "as a fascinating biotechnological experiment that might play a role in creating future ecosystems," rather than restoring those of the past (Heise 2016, p. 211, my emph.). Similar sentiments are echoed by some in the so-called ecomodernist or ecopragmatist camp such as tech enthusiast, entrepreneur, and de-extinction advocate Stewart Brand, who urges: "Don't mourn, organize" (Brand 2013). Environmental and conservation movements, Brand laments, have unwisely "mired themselves in a tragic view of life," forever fixating on the mistakes of the past. If the extinction of the passenger pigeon "broke the public's heart," Brand suggests, then the pigeon's revival through technologies of de-extinction might well "shake them out of it." Moreover, such a project could be "fun," Brand argues. "Could improve things. It could, as they say, advance the story"-a progressive and hopeful story to overwrite the tired declensionist narrative (qtd in Rich 2014). Broken hearts can be mended by cutting-edge technology.

So, again: why the stubborn resistance to mourning? Whence the injunction against looking backward, toward the past and its (sometimes heartbreaking) lessons? Grief is not merely protracted sadness, and the particular features of environmental grief may make it especially difficult to confront and process. Grief and mourning are responses to a world that has been radically transfigured. As Nancy Menning argues, environmental loss is complex, owing to the intermingling of grief with guilt for our own complicity, and perhaps anger at the wrongdoing, or indifference, of others. "We are often complicit in these losses, if only by virtue of living in the Anthropocene ... Guilt entwines with sorrow, complicating the grieving process" (Menning 2017, pp. 39-40). Moreover, grief over issues like climate change is somewhat unique in that it is unlikely to lessen over time: "because of time-lags in the climate system, things will get worse for a long time to come, whatever we do" (Read 2019). On some accounts, for grief to do its work-for its transformative power to effect change in the mourner that reflects the magnitude of the loss-there must be a genuine reckoning with the irreplaceable nature of what is lost. Moving too quickly to closure, or seeking something new or different to replace the loss, 
may distort the grieving process or obstruct its transformative work. ${ }^{4}$ For example, efforts to de-extinct species may express an impulse to replace what was lost, and thereby short-circuit the process of grief and its potential to catalyze change. Where environmental mourning is tinged with other complex or unpleasant responses, opportunities to confront these emotions through commemorative rituals or funerary rites may help to spark change- the kind of individual and collective transformation that might mitigate similar losses in the future (Hance 2016). ${ }^{5}$ On the other hand, the uncomfortable mix of emotions can easily engender avoidance of grief.

Other factors may contribute to evasion and denial. In his commentary on religionists' lack of attention to the topic of extinction, Jenkins suggests that extinction sticks in the craw for human exceptionalists. "Making good on human exceptionalism," he writes, "perhaps seemed to require staying silent as Passenger Pigeon, Heath Hen, Ivory-billed Woodpecker, Bald Eagle, and California Condor fluttered at death's door" (Jenkins n.d., p. 5). Even Christian hymns and sermons attesting to divine attention to the sparrow serve only to reinforce our conviction that if God takes notice of so lowly a creature, God's concern for humans must surely be boundless. The diagnosis of human exceptionalism seems plausible in light of future-facing, progressive narratives that hold out the possibility of re-creating species-lauding humanity's godlike power to reshape the planet-while exhorting us not to dwell on species death. Death, especially mass death—especially human-caused mass death—does not advance the story.

\section{Climate Humanism on a Deathless Planet}

A certain grief-resistant strain of humanism, I would argue, similarly inflects some of our current discourse on climate change, especially (though not solely) climate reporting aimed more broadly at the public. At its worst, this discourse tip-toes to the edge of collapse porn, almost relishing the dark side of climate change- "like a voice from a nightmare" - with grave reminders of just how bad the situation is (Watts 2019). Yet the news is delivered with a certain air of bravado, as if to test the limits of what the reader can stand. A hallmark of climate humanism is its implicit disavowal of mourning for the Earth and its nonhuman inhabitants in favor of fear that can channel all our energies toward safeguarding human civilization. Some writers of this genre insist that the planet does not need humans to save it. After all, Earth is a 4.5-billion-year-old space rock that has withstood catastrophes far more dramatic than our current period of anthropogenic climate change, which appears against this backdrop as a mere geological blip, an "unimportant oscillation" (Latour 2018, p. 72). On this account, it is ourselves we must save. Earth itself will cycle on. We know this because we have grasped the long view of Earth — a planetary perspective-provided by sciences like geology or astrobiology. Thus, Neil deGrasse Tyson opines in a widely shared Earth Day tweet that environmentalists' perennial call to save the Earth is "odd." "Planet Earth," he insists, "survives massive asteroid strikes-it'll survive anything we throw at it. But Life on Earth will not." To whom or what does "Life" refer in this context? More to the point, what could it mean for "Earth" to continue without "Life"? What sort of Earth would that be?

It is Planet Earth that is predictably spoken of in these terms-a virtually timeless, deathless, and resilient entity with a long history of upheavals that preceded humans' arrival on the scene. Earth-as-planet recalls Bruno Latour's critical commentary on Earth as seen from space, or from the outside-a kind of spaceship Earth that Latour labels "nature-as-universe." Our planet surveyed as if from a rocket ship is distinct from nature-naturing or nature-as-process, a terrestrial vision of Earth that grasps its immediacy and vitality. "It is about the planetary vision that one can say, considering things 'from above,' that it has always varied and that it will outlast humans." The Terrestrial Earth,

4 Following Freud, grief that does not resolve in some way over time or that takes on an addictive quality is sometimes referred to as melancholia, to distinguish it from mourning.

5 Emerging rituals and commemorations like Species Remembrance Day and theatrical stagings of funerals for extinct species are examples of recent attempts to confront and process environmental grief. 
on the other hand, "does not allow this kind of detachment" (Latour 2018, p. 72). Earth as seen from the outside-one exoplanet among others, perhaps—is the Earth that we mistakenly believe we can somehow escape should it become inhospitable to us (even while it cycles on). Or perhaps we will simply reboot Earth with emerging technologies like geoengineering. Elite members of human civilization stand to benefit most from this detached off-planet perspective which renounces any notion of a shared world in favor of a headlong flight from climate threats. By contrast, the Terrestrial account foregrounds human interaction with and dependence upon nature, effectively decentering humans and returning agency to nature and the nonhuman realm.

In his remarkable book, The Unconstructable Earth, Frédéric Neyrat-who otherwise takes issue with many of Latour's theoretical contributions ${ }^{6}$-offers a similar diagnosis. Earth as viewed from the extraplanetary position is part and parcel of a stance Neyrat calls "geo-constructivism," and an accompanying posture of anaturalism that refuses to recognize nature as a category at all. "It's as if the geo-constructivists view themselves as residing off-planet, outside the Earth," Neyrat writes, "without any kind of vital relation with the ecosphere, detached and separated as far away as possible from the Earth object to be reformatted" (Neyrat 2019, p. 5). The anaturalism of the geo-constructivist position results in a dubious kind of environmentalism "without nature," or "ignorant of it" (Neyrat 2019, p. 4). ${ }^{7}$ Nature is simply a nonbeing, "an inanimate and mathematizable material, upon which a human fashioning is applied that always tends toward extending the limits of the possible and transforming the impossible into the possible" (p. 5). Geo-constructivist technologies, ranging from synthetic biology to climate engineering, seek not merely to "conquer nature but to remake it" (p. 5). Earth is rendered "nonterrestrial," something to be steered or piloted; an entity to be remade-reconstructed—through geoengineering, carbon capture, and the proposed de-extinction of lost species (p. 49). The survival of humanity—or, again, elite representatives thereof-becomes the overriding imperative of this post-environmental ecopragmatism. This emphasis on the long-term survival of an elite, globalized anthropos living on an exoplanetary space rock (if not Earth itself, then some reformatted version thereof, or another interchangeable planet altogether) suggests the affinities between geo-constructivism and what I call climate humanism.

While Neyrat does not put it in precisely these terms, the implication is clear: Planet Earth is rendered virtually unmournable, because it was never really alive or is deemed essentially deathless. Nature and nonhuman life are akin to the derealized bodies described by Judith Butler, entities that are "always already lost or, rather, never 'were,' and they must be killed, since they seem to live on, stubbornly, in this state of deadness" (qtd in Cunsolo 2017, p. 171). The Promethean idea that an extinct species—something dead—could be technologically resuscitated, and the end-product deemed just as good (or better!) than the original, provides a disturbing case in point. That Earth itself could be remade, or simply exchanged for another habitable world, carries the same troubling suggestion. Earth stands ready to be reconstructed as Earth 2.0. "Death itself," Neyrat writes, "no longer has a place within this scientifico-discursive apparatus... The death of nature will simply have been the necessary step toward the programming of its controlled resurrection" (Neyrat 2019, pp. 53-54). Earth might as well be Mars—or Mars a perfectly acceptable substitute for earth—as if Earth were somehow "lacking life" or "already dead" (p. 52).

Often, as both Neyrat and Latour suggest, the geo-constructivist impulse-like climate humanism - exhibits both a defensive and a faux-courageous quality, stemming from its refusal to recognize shared vulnerability with other lifeforms, or even, in some cases, our common predicament

6 Neyrat's critique particularly targets Latour's dalliance (if that is what it is) with ecomodernism, as seen in his essay "Love Your Monsters: Why We Must Care for Our technologies As We Do Our Children," published as a contribution to a volume edited by ecomodernism's founders, Ted Nordhaus and Michael Shellenberger.

7 On Neyrat's account, this erasure can be effected either through the distancing and objectifying move of Earth as an exoplanet in space or by positing radical entanglement and a generalized hyperconnectedness that sees humans as everywhere and always intermeshed with Earth-or some combination of the two. Neyrat rejects both in favor of an ecology of separation, as he terms it, that allows an unconstructed Earth to reclaim its alterity and singularity. 
with fellow humans. When Anthropocene commentators of the climate humanist variety pinpoint the human enterprise as that which is truly at stake, this insight is very clarifying. Let us be honest, they say, about what "we" really fear losing and how we might minimize the losses. As Butler argues, that which we do not grieve reveals a lot about us. "I am as much constituted by those I do grieve for as by those whose deaths I disavow" (qtd in Cunsolo 2017, p. 13). In an era of climate change and extinction, the category of ungrieved and ungrievable entities has expanded to include "the melting of ice caps, the permanent loss of biodiversity through human-induced extinction, and the changes in lands all over the world because of climatic shifts and variability" (Cunsolo 2017, p. 174). These deaths "often escape the literature around mourning, and our own conceptualizations of mournable bodies" (Willox 2012, p. 146).

As an example of climate humanism largely detached from mourning for life beyond the human project, consider the work of David Wallace-Wells. Wallace-Wells is perhaps best known as the author of an article that appeared in New York Magazine in 2017 called "The Uninhabitable Earth," and a subsequent book by the same title. His reporting has shocked and angered many readers, including some climate scientists, who found it unnecessarily hopeless. His widely quoted tagline is now familiar to many: climate change "is worse, much worse, than you think." In light of this assessment, we might expect to find in his work a meditation upon grief for the "Earth" we are making uninhabitable. Yet there is surprisingly little concern for, or even acknowledgment of, nature and the nonhuman world in Wallace-Wells' writing, or in his discussions elsewhere of what motivates his climate concerns.

Regarding his turn to climate change as a topic of research, Wallace-Wells reports that he happened upon the climate story by accident (Klein 2019b). ${ }^{8}$ He sensed there was a gap in climate reportage and that mainstream media sources were underplaying the alarm. His interest, he notes, was that of a "competitive journalist," not that of an environmentalist-a term he regularly dismisses (Wallace-Wells 2019; Swisher 2019). ${ }^{9}$ He calculated that by breaking such a story-filling the news gap—he could "punch up" to top tier journalism (Klein 2019b). (His brother, Benjamin, is a veteran journalist and staff writer for the highly regarded New Yorker magazine). On Wallace-Wells' reading, climate change had been badly communicated to the public as a slow-moving threat having largely to do with sea level rise. Hence, if you did not live directly on a coast, you could blithely assume you were immune from devastating impacts. Wallace-Wells describes himself as a lifelong urbanite, a New Yorker, who considered his city a "fortress," a place outside of nature that could never be infiltrated by its forces. He confesses that he came of age as "an end of history kid," a believer in progress who felt "in my core, that over time, things got better, people got richer." He came to realize that no one should assume they are safe from climate change "no matter how fully defended [they] are" (Klein 2019b). As someone who imagined himself insulated from nature, he was genuinely shocked to discover the many terrifying, cascading effects of climate change beyond sea level rise: new mosquito-borne diseases, a plunging GDP, geopolitical upheaval, crop failures, etc. In other words, when Wallace-Wells says that climate change is "worse, much worse, than you think," he means it is much worse than he thought. Uninhabitable Earth, it appears, is the product of his realization of his own vulnerability.

Yet, what is striking about Wallace-Wells' alleged awakening is how seldom it acknowledges (much less laments) harms and losses to the natural world. By his own admission, very little of the book deals with "'nature' per se" and "none" of it concerns animals (Wallace-Wells 2019, p. 39). "I tend to think when you're at the top of the food chain, it's okay to flaunt it" (Wallace-Wells 2019, p. 7). He discusses climate-induced devastation of insect populations, for example, in terms of consequences for the human food supply. When the topic of extinction is raised, he describes himself as "not invested in the fate of animals" (Klein 2019b). As with generations of environmental writers before

8 Wallace-Wells made these remarks in an interview on the Ezra Klein show on 24 March 2019. https://www.stitcher.com/ podcast/vox/the-ezra-klein-show/e/59194732.

9 Wallace-Wells makes similar comments about his motivations for reporting on climate in the interview on the Ezra Klein show, cited previously. 
him, Wallace-Wells understands fear and alarm to be powerful vehicles for change, and there is indeed considerable stoking of fear in his climate reporting. In interviews, he repeatedly assesses climate scenarios as "really, really bad" and "terrifying," predicting a future "hellscape" of a planet. "The facts are hysterical" (Wallace-Wells 2019, p. 32). But his expressions of fear are framed primarily as threats to human survival; solutions, insofar as he offers any, stake a claim to technologies of carbon removal and faith in progress as the antidote to fatalism. His awakening remains incomplete at best, in its refusal of vulnerability and its repudiation of grief for the natural world. He aspires to build an all-hands-on-deck movement among people like himself who do not identify with "environmentalism" or have never considered themselves lovers of nature. He calls for "lowering the price of admission" to joining the climate cause; that is, we should not expect all comers to have a stake in the same issues, or even to concern themselves with life beyond the human enterprise (Klein 2019b).

Young climate activists, like Varshini Prakash who became involved in climate activism at the age of 19 and now leads the youth climate movement called Sunrise, can be heard expressing similar sentiments. Prakash describes coming of age in an era of climate crisis, explaining that the youth movement birthed by such trauma aims at human self-preservation, not "saving the planet." "The planet," she observes, "is going to be here long after humanity is dead and gone" (Klein 2019a). Prakash-more so than Wallace-Wells-acknowledges that nonhuman species also suffer from climate change, yet the tendency is to rally around preserving civilization. She laments that the climate movement has been too tightly coupled with the environmental movement. "It feels like for the last 40 years it's been gated to the realm of environmentalism. Like it's about saving the environment or preserving the environment, not salvation for humankind more broadly and preserving our way of life" (Klein 2019a).

To be sure, there is value in sounding the alarm on climate change, particularly for those who, like Wallace-Wells, have remained oblivious to its kaleidoscope of impacts. ${ }^{10}$ There is also much to commend in the grassroots work of the Sunrise movement. The big tent approach sounds perfectly reasonable. Time is short, after all, and we cannot afford to scrutinize and quibble over the values that motivate action on climate change across a spectrum of personal and political commitments. But there is also a troubling strand of accommodationism to anthropocentric, instrumental values in these approaches to climate change, and in some cases, a disconcerting lack of identification with an Earth that retains a vital living presence. It is difficult to imagine authentic change emerging from movements that routinely foreground human civilization, and fail to mourn catastrophic losses to the living world beyond humans. Genuine, attentive mourning for losses beyond our own might work against "a deeply ingrained habit of seeing the natural world as an object, a thing somehow detached from our own lives" (Christie 2013, p. 71).

A far more extreme and rather chilling example of preoccupation with sheer survival, and pronounced resistance to solidarity, is offered by Douglas Rushkoff, a media theorist and novelist associated with the cyberpunk movement (a genre of science fiction typically oriented around a high-tech, dystopian future). Rushkoff's account appears in the handbook of the Extinction Rebellion movement, This is Not a Drill. By way of background, Extinction Rebellion (XR) is sometimes seen as part of a darker, brooding segment of the climate movement. ${ }^{11}$ Grief and mourning are built into its guiding principles and central to its activist philosophy. References abound to a "dying planet," "ecocide," and activism born of "ferocious love" for the land, and XR protests often stage funeral processions and enact rituals of grieving (Farrell et al. 2019). Gail Bradbrook, one of the founders of XR, speaks candidly about her use of psychedelic drugs to open herself to environmental grief and trauma, but also to her own "deeply felt sense of peace, oneness, and unity with the planet" (Bradbrook 2019).

10 Wallace-Wells at times compares his approach to that of Rachel Carson. It is worth noting, however, that the title, and much of the content, of Silent Spring (1962) addresses suffering and losses to nonhuman life as well as human.

11 For a similarly somber and highly creative take on environmental crisis, see The Dark Mountain Project founded by Paul Kingsnorth and other writers, artists and activists: https://dark-mountain.net/. 
In his essay for the XR handbook, Rushkoff brings these values to his analysis of elitist escapism and (literal) fortress-building (Rushkoff 2019). In fact, his essay is a perfect example of Latour's portrait of elites who loudly dismiss climate science while quietly hoarding the lifeboats. These people "have been so thoroughly convinced that there would be no future life for everyone," Latour writes, "that they have decided to get rid of all the burdens of solidarity as fast as possible" (Latour 2018, p. 18). Rushkoff describes receiving an almost unimaginably lucrative invitation to deliver a keynote address at a deluxe resort to an assembled group of investment bankers. Rather than being shown to the stage, he is ushered into a seminar room, where groups of wealthy bankers are brought directly to him-men (they are all men) from the "upper echelon of the hedge-fund world" (p. 58). They are not interested in hearing his prepared comments. Instead, they interrogate him about surviving the coming climate crisis. Some of these men, he learns, are already constructing luxurious underground bunkers. Others solicit his advice regarding which regions of the world might be spared the worst climate disruptions. How to protect their food supply. What to pay their security forces when money becomes worthless. One asks him pointblank: "How do I maintain authority over my security force after the event?" (p. 59). The event. Rushkoff realizes with horror that these men, like futurists Elon Musk and Ray Kurzweil, have invested in the future of technology—and thus, the future, generally, as they understand it-with an eye to one thing only: their own escape. In seeking escape, he writes, they were plotting to transcend "all that is human: the body, interdependence, compassion, vulnerability, and complexity" (p. 60). Needless to say, nonhuman beings do not enter into their plans at all-except, possibly, as food.

I am not suggesting that Wallace-Wells (or the Sunrise movement) partakes of the pathology of Rushkoff's hedge fund preppers. There are varying degrees of human-centeredness, fortification, and resistance to vulnerability and solidarity. But even relatively benign strains of climate humanism exhibit a striking dearth of feeling for a living Earth—distinct from a deathless planet—and a problematic emphasis on protecting what Prakash often calls "our way of life." While milder forms of climate humanism invoke human civilization as the primary object of preservation, the builders of gilded fortresses constrict the circle ever more narrowly, to include only elite individuals like themselves who believe they have the means to escape.

With these examples of the spectrum of resistance to grief and mourning in mind, I want to turn for the remainder of this essay to a more reflective and sober form of Anthropocene storytelling and the fragile but potent forms of hope made possible through the work of grief. Among the tales of climate mourning and protest that have recently made headline news, few can compete with the story of a little Icelandic glacier and its untimely demise. It is to this remarkable story that I turn next.

\section{Grief for a Living World: The Death of a Glacier}

Scholars who study environmental grief and mourning argue that we can expand our conceptions of what counts as mournable entities by attending to, reframing, and even practicing in our own lives, the work of mourning. "One possible avenue for reconstituting non-human bodies as grievable within the climate change arena is through the incorporation of the work of mourning in research, practice, public discourse, and action ... extend[ing] the concept of a mournable body beyond the human" (Cunsolo 2017, p. 173). The story of Okjökull glacier, or "OK" for short, provides a good example of what this work might look like among activists, scholars, and political leaders. The wide circulation of the story of OK glacier's demise owes much to the brilliant podcasting team of Cymene Howe and Dominic Boyer of Rice University, both of whom work at the intersection of anthropology and the energy humanities. ${ }^{12}$ A funeral rite for the vanished glacier was held in August 2019, and included a solemn hike up OK mountain where the glacier had once lived. Howe and Boyer, accompanied by a group of mourners, ascended the mountain. The mourners included Howe and Boyer's young daughter, as

12 Howe and Boyer host the podcast series "Cultures of Energy." 
well as other children; also present were the prime minister of Iceland, various scholars and artists, and a glaciologist who presented an official death certificate. The glaciologist spoke privately to Howe about the strangeness of pronouncing the glacier's death when no previous declaration of its birth, no christening, had ever occurred (Howe and Boyer 2019). ${ }^{13}$ "Excessive heat" was listed as the cause of death, with humans as the implied proximate cause: "Nothing was done to save it" (Johnson 2019). Interestingly, in a documentary about Okjökull, created by Howe and Boyer with Icelandic filmmaker Ragnar Hansson, the events surrounding the glacier's death are narrated in the personified (and thickly accented) voice of OK mountain. While giving a human voice to inanimate features of nature might strike some as problematically anthropomorphic, the film creates a compelling sense of the mountain as a living entity whose once-animate glacier is now a casualty of human indifference.

With or without christening rituals that declare glaciers officially alive, the perception of glaciers as living, even divine, entities capable of sustaining and destroying life is common across many cultures. "The glaciers' movements and sounds caused them to be perceived as animate forces worthy of respect and veneration by those living nearby," writes Elizabeth Allison in an essay that explores how climate change is reconfiguring the spiritual dimensions of glaciers (Allison 2015, p. 496). Finely honed rituals and rules of engagement with glaciers are observed in many such cultures, regarding, for example, when one may speak in the glacier's presence, how glacial water is to be collected, and how pilgrimages should be conducted. Among cultures that traditionally associate their deities with mountain glaciers, the melting of a glacier might be interpreted as punishment for moral transgressions. An overabundance of tourists traversing the mountain, or a lack of piety, awe, or reverence might be seen to trigger a glacier's decline (Allison 2015). Even glaciologists who otherwise insist on the abiotic nature of glaciers, speak and write in terms suggestive of animacy. Scientists describe glaciers as moving and growing; they are spoken of as repositories of memory, providing a record of past ages and environmental conditions, much like tree rings. "They also 'crawl' and have 'toes'; when they break off at the ablation edge, they are said to have calved," like an animal giving birth (Johnson 2019).

A glacier that no longer crawls or calves, that no longer records memories, is a dead glacier. Only something deemed vital and living can be mourned as dead, and rituals of mourning, properly done, may effect a change in the living. Meaningful change is what Howe and Boyer, and the other mourners at Okjökull, hoped to achieve. A commemorative plaque created to mark the glacier's death sends a message to the future: "We know what is happening and what needs to be done. Only you know if we did it." During the ceremony surrounding the placement of this plaque, children were asked to come to the front of the crowd. Howe addressed them, saying "We need to understand our relationship to the world in ways we haven't had to in the past. We need to be able to imagine a new future" (Johnson 2019).

In The Secret Life of Glaciers (Jackson 2019), M Jackson relates the numerous stories she collected among Icelanders who perceive their glaciers to be sentient, living beings. Jackson's storytelling resonates with additional details of the funeral rite and pilgrimage to mark the death of Okjökull. These details, as told by Howe, have an intriguing mythic quality. Indeed, OK's story suggests a useful framing for thinking about hope, grief, and the possibility of moving forward into the future, while maintaining an intimate connection to the past. As noted previously, the ceremony for OK entailed a long walk up the mountain, culminating in the installation of the commemorative plaque. The last $100 \mathrm{~m}$ of the procession took place in silence, in accordance with Icelandic tradition. Tradition also dictates that climbers may make three wishes as they silently approach the summit, and that they are not to look backward as they ascend. Climbers who obey these rules are said to have their wishes fulfilled. OK's rocky terrain made the hike physically challenging, and as Howe explains, she was not

13 These and other details of the ceremony are described by Howe in a segment of the "Cultures of Energy" podcast recorded soon after the Icelandic ceremony. 
certain from one moment to the next whether her daughter had been able to keep up and was still somewhere close behind her. She wanted desperately to turn around, but also wished to respect the custom of forward-facing silence. On Howe's own interpretation of the ritual, ascending the mountain became a "metaphor for moving forward in the climatological apocalypse." "We have to keep moving forward," she says, "with whatever kinds of solutions we can come up with." Yet the injunction to keep going was "frustrating" as she became increasingly worried about her daughter's progress, somewhere behind her. Finally, still facing forward, she tentatively extended her hand backward, not knowing who was behind her or how they might react. A second later, she says, she felt her daughter's small hand grasp her own. "I started crying" (Howe and Boyer 2019). ${ }^{14}$

Readers of mythology may have a sense of déjà vu upon hearing this tale. I was immediately reminded of the legend of Orpheus and Eurydice as told by the third century BCE Greek poet Apollonius. Orpheus was an unparalleled musician who protected the Argonauts from the bewitching song of the Sirens. So enchanting was the music of his lyre that it saved the sailors from the Siren's deadly voices. According to other details of Orpheus's life, his young wife Eurydice is fatally struck by a viper shortly after they are wed. Inconsolable, Orpheus leverages his musical reputation to bargain for the return of his bride. He is allowed to enter the world of the dead, where he encounters a veritable who's-who of the underworld, all of them enchanted by his lyre. "The dog Cerberus relaxed his guard" and Tantalus "forgot his thirst" (Hamilton 1942, p. 140). Above all, Pluto, the ruler of Hades, was moved to tears. Orpheus's wish to retrieve his wife is swiftly granted and Eurydice summoned-but on one condition: Orpheus must not look back at her until the two have passed the gates of hell. As with Howe's narration of the mountain pilgrimage, Orpheus is desperate to sneak just "one glance to make sure" that Eurydice is still behind him (Hamilton 1942, p. 141). He resists, and gradually the darkness gives way to grey light, and then to sunshine. Certain that they have crossed the threshold, Orpheus steps into the light. He turns to look at Eurydice, but it is too soon-she is still in shadow. He reaches for her, but the darkness quickly reclaims her. The gods will not grant Orpheus another trip to the underworld.

It seems that there is no comfort whatsoever in this story of crisis and shattered hope, of grief compounded by a second wave of irrevocable loss. Other myths similarly warn us of the dangers of looking over our shoulder, toward the past. In the Old Testament, Lot's wife famously defies the directive not to look back and is transformed into a pillar of salt, the very symbol of paralysis. Popular readings of these stories enshrine a progressive, almost evolutionary edict to advance linearly, to evade death and its grave reminders, through sheer forward motion-or at least the appearance thereof. The prey animal, pausing to glance backward, is swiftly overtaken by the predator. But I wonder if we might be wrong to read these tales as simple injunctions against looking back-as if doing so constitutes a loss of faith, while forward motion is synonymous with hopeful action. We might complicate these readings of a forward-facing imperative and future orientation by reflecting more deeply on the nature of grief and hope. Other voices-journalists, activists, feminists, artists-can tell us a different, more humane, story about these emotional states, and what it means to advance. For additional insights into the nature of crisis, and the power of mourning and hope in their complex entanglements with the past, present, and future, I turn to journalist Dahr Jamail, and writer and activist Rebecca Solnit.

\section{The Gift of Grief in the Anthropocene}

It is difficult not to compare Wallace-Wells' climate reporting with that of Dahr Jamail, author of The End of Ice. Their books on climate change both appeared in 2019, and the two works are often reviewed and discussed in tandem. Jamail's book opens with a dedication to "future generations of

14 Howe's telling of the story is, on the whole, much more lighthearted and jocular than my narration here. Nevertheless, I found the story very moving. 
all species," and indeed the plight of nature and nonhumans figures prominently in his grief-soaked writing. Jamail frequently draws on the metaphor of "witnessing," likening climate mourning to the inevitable loss of a terminally ill friend. A concluding chapter, simply called "Presence," offers a more extended reflection on what it means to love, and bear witness to, an Earth that "may well be dying" (Jamail 2019, p. 216). Jamail embraces what he calls the gifts of crisis which for him include being more present, even feeling more alive, than ever before in the midst of grief. These gifts "are the conditions that make possible widespread shifts in political identity, purpose, and consciousness" (Jamail 2019, p. 216). Being present with Earth is a way of remaining connected to sorrow. Accepting Earth's probable decline "opens into a more intimate and heartfelt union with life itself" (Jamail 2019, p. 219). He describes this experience as "falling in love with the Earth in a way I never thought possible." Witnessing allows him to rededicate himself to his work each day, even if it means "my heart breaks, over and over again" with each successive wave of loss (p. 219).

Drawing on the contemplative traditions of ancient monks, Douglas Christie describes the attentive practice of dwelling in grief and tears as "penthos or katanyxis," Greek terms suggestive of a "profound piercing of the heart" and a paradoxically joyful form of sorrow and penitence (Christie 2013, p. 74). Allowing oneself to grieve, and especially giving oneself over to honest, heartfelt weeping, was considered essential to ascetic practice and spiritual renewal. Seeing the world through tears, with a wounded heart, Christie argues, is a fitting contemplative ecological practice in today's world, one that fosters a sense of being alive and awake to the beauty and fragility of nature. "Tears for lost places, for a whole lost world of possibilities. Also, tears born of gratitude for what has been, for what might yet be retrieved and restored. Tears as a source of renewal. Tears as gift." (Christie 2013, p. 74). The ancient practice of memento mori, a sustained reflection on mortality, finitude, vulnerability, and death, was thought to reorient the practitioner toward meaning, purpose, and one's own limits, creating a sense of urgency, or what the monastic tradition calls compunction: "learning to live continuously against a horizon of ultimacy"; to be carried "across a threshold on the far side of which lay a qualitatively different existence" (Christie 2013, p. 76).

The End of Ice is a memento mori for nature, an extended meditation on heartbreak and the sense of compunction that brokenness makes possible. Jamail is no stranger to trauma, having spent several months as one of very few unembedded journalists in occupied Iraq. But long before that phase of his career, Jamail had developed a deep attachment to mountains. His writing expresses a climbers' love for landscapes whose desecration he feels compelled to document. Reflecting on the similarities between his work in Iraq and his turn to writing about climate change, Jamail describes the shattering of hope that made way for a generative form of grief. This grief, in turn, gives birth to a new "hope-free" form of hope. "I had hoped my work in Iraq would contribute to ending the U.S. occupation ... I had hoped, too, that writing climate dispatches and bludgeoning people with scientific reports about increasingly dire predictions of the future would wake them up to the planetary crisis" (Jamail 2019, p. 217). Surrendering hope, he says, was difficult, but he came to realize that hope, as he had previously experienced it, was an impediment. He turns to the Canadian storyteller Stephen Jenkinson, a leader in palliative care counseling who grasps the imperative "to burn through the false choice of being hopeful and hopeless." Grief, Jenkinson concludes, "is required to proceed" (qtd. in Jamail 2019, p. 218).

Jamail's initial tactic of "bludgeoning" readers with grave reports to force an awakening is reminiscent of Wallace-Wells' approach. But to dwell in grief and bear witness to devastating losses beyond the threats to human civilization, as Jamail does, is to renounce a defensive stance. An expansive sense of grief and love for Earth in its living - and possibly dying — state can catalyze the "extraordinary alchemy" that turns grief and despair into "profound activism"-a kind of forward motion that does not lose sight of the sorrow that drives it (p. 217). Jamail's language of presence, of being-with Earth in a period of decline, is echoed by other scholars in the environmental humanities who invoke metaphors of palliative care, and hospice- of "de-colonizing" extinction rather than pressing forward with controlling, heroic measures to save the last members of a species at all costs (Parreñas 2018). Thom van Dooren worries about the forms of "violent-care" entailed in all-out efforts to pull species 
back from the brink of extinction, at great pain and sacrifice to the individual animals themselves (Van Dooren [2014] 2016). He and Deborah Bird Rose urge us to "keep faith with the dead" as an expression of resistance to the techo-allure of de-extinction strategies. Those, like Stewart Brand, who would steer us away from mourning are engaged in "an ostentatious display of bad faith toward both the living and the dead." Dismissals of mourning

buy into what the environmental philosopher Daniel Innerarity has called "false motion." Here, the bright promise of new technologies, of doing something, undermines the genuine reflection needed to get somewhere better—not just different (Van Dooren and Rose 2017, p. 376).

Elsewhere, Rose describes the delicate and critical weave-work that is accomplished by death narratives, as in stories traditionally told by Indigenous cultures that situate death in place and time, memory and wisdom. Here, death is turned back toward life, through acknowledging connectivity between the deceased and the living, the past and the future. Turning away from death, erasing rather than honoring it, amplifies death and twists it into grotesque forms. "Death binds living beings into an ecological web," she writes, but ecological catastrophe-man-made mass death-brings "cascading ruination of both past and future life and death" (Rose 2011, pp. 91-92). The hallmark of a death-denying culture is that it treats the resulting wreckage as merely the acceptable "by-product or collateral damage" of progress toward a non-existent "better world" - a future that cannot come into being because it has been severed from its own past (p. 89).

Environmental philosopher Ben Minteer similarly questions the fixation of de-extinction enthusiasts with a "cheerier story, a more uplifting narrative driven by sunny acts of biological creation and ecological recovery" (Minteer 2019, p. 109). Our attraction to technologies that advance the upbeat storyline is an evasion of the hard lessons of extinction, lessons that can only be absorbed by sitting with the mistakes of the past, and with the deeper moral problems of which extinction is a symptom. Meditation on extinction is a powerful reminder of "our fallibility and our finitude" (Minteer 2014, p. 261). We might say that de-extinction denies the irreversibility, the irrevocable nature of species death, rendering these creatures not fully alive-and therefore ungrievable-even while they live. It mistakes mourning for inaction, or failure.

Dahr Jamail sometimes describes the proper response to climate change as learning how to fail. By this he means, in part, learning to live in accordance with what is rather than what might be in the future-doing your best, even knowing that it might all go down in flames. Attunement to what is necessarily entails an admission that you do not know what might happen. It is within this space of uncertainty that grief and hope co-exist. We act without knowing whether what we do actually does anything. But nor can we be certain that what we do does nothing. "I surrendered my attachment to any results that might stem from my work" (Jamail 2019, p. 219).

\section{Falling Together}

Jamail's (somewhat Buddhist-sounding) reflections on loss, grief, and hope share certain affinities with Rebecca Solnit's discussion of what she calls "hope in the dark," the title of a book originally published in 2004, and reissued with updated material after the election of Donald Trump (Solnit 2016). Among the many topics her work has canvassed over the years, Solnit has a particular interest in the meanings to be found in disasters like Hurricane Katrina or the Fukushima nuclear accident. Her work does not radiate the searing grief of Dahr Jamail—in fact, some might deem it not nearly dark enough for our times-but the parallels are instructive, and they suggest how we might orient ourselves toward the future without forgetting where we have been. She points us to the many astonishing and unanticipated events that have unfolded in recent years: the Arab Spring, Occupy Wall Street, Black Lives Matter, and more recently, the arrival of Brexit and Donald Trump. Echoing Jamail, she describes the "proximity of death in shared calamity" that nevertheless creates a sense of purpose, joy, and vitality (Solnit 2020a). Solnit recognizes that "there is meaning as well as pain in sadness, mourning and grief, the emotions born of empathy and solidarity" (Solnit 2020a). Recently, 
in the midst of the Covid-19 pandemic, Solnit was a reassuring voice to many, as she turned to reading fairytales in nightly online sessions that attracted enormous (virtual) crowds of listeners completely rattled by an indefinite lockdown. Fairytales—a genre of never-ending stories- "felt like the right kind of narrative" in a sustained period of "not knowing" (Solnit 2020b).

While some of the developments Solnit reflects upon are shocking in ways that appear decidedly negative, they nevertheless underscore her point about the fundamental unpredictability, the sheer nonlinearity, of life and what we call history. Uncertainty is what makes hope possible. Novel forms of protest and resistance have arisen around the world, and with them counter-resistances and counter-protests, in ways no one anticipated. Hope, Solnit writes, "locates itself in the premise that we don't know what will happen, and in the spaciousness of uncertainty is the room to act" (Solnit 2016, p. xiv).

In particular, Solnit is fascinated by the way people actually behave during crises, and she is particularly drawn to a certain mysterious emotion, a peculiar joy, that often lights up the faces of those who experience disaster. The stories we have been told about so-called human nature lead us to expect that in the midst of crisis, humans devolve into crass social Darwinists and savage Hobbesians. But disasters can often rivet people to the present moment in the best possible way. Solnit, like Jamail, sees crisis as giving rise to a "super-saturated immediacy" and a deep sense of connection. The "violent gift" of such experiences, Solnit writes, "is that you feel more alive." So do others around you-there is a shared experience, not of falling apart, but what Solnit calls "falling together" (Tippett 2016). A rejection of this joyful but grieving solidarity—an outright refusal of falling together-characterizes the investment bankers Rushkoff describes, and the elites Latour depicts as abandoning a shared world. As Rushkoff's account suggests, some of us do devolve into barbaric Hobbesians defending only our immediate territory and interests-or hoarders of face masks in the midst of a pandemic. And often it appears that the more secure and insulated we are-in plainest terms, the wealthier we are- the greater the resistance to acknowledging vulnerability. As Solnit observes, "one of the primary uses of wealth has always been to buy your way out of the common fate" (Solnit 2020a). The idea that we and other humans, and that humans and nonhuman life share a common fate is understood only as an infringement on freedom. Thus, as with Rushkoff's investment bankers, technology becomes a vehicle not of collective flourishing but of individual, material survival. For these men, there is simply nothing to grieve.

An absence of grief is, oddly enough, symptomatic of an underlying certainty, whether it is the certainty of optimism or that of despair-certainty that the future will simply be a continuation of the status quo or will decline from it. Both optimism and despair can serve as grounds for doing nothing, or simply doing more of the same. Hope, therefore, is distinct from optimism. Solnit explains that the title of her work "hope in the dark" is an effort to reclaim darkness from its negative, and especially racist, associations. Disaster rivets us to the present moment, but the future is veiled in darkness. This is the darkness not of the tomb, but of the womb-a place of mystery where something novel may spring to life. Significantly, she argues that hope has been misunderstood as singularly oriented toward the future. In truth, hope is often grounded in the past, for it is a function of memory. For this insight, she credits the work of theologian Walter Brueggemann, who understood that the past, and our memory of it, confirms that we did not know what was going to happen, before it happened. "Memory produces hope in the same way that amnesia produces despair," Brueggeman writes (Solnit 2016, p. xix). It may sound obvious or even trite to point out that we do not know what will happen before it happens. And yet the way we routinely narrate history-how we tell stories generally-makes it appear as if events were inevitable, as if they unspooled, unerringly, according to some inner logic. "We pretend that life like art has plots and we know how the story ends, whether it's an election or a cultural shift or the outcome of any major event," Solnit writes, "and we often err not on the side of caution but on the side of conventionality: the future will look like the present"(Solnit 2020b). But in its complexity and its unforeseen shifts, history is more like weather than like checkers (Solnit 2016, p. 61). The forward-looking energy that we rightly associate with hope springs in part, then, from our 
clear-eyed recollection of having been surprised by events in the past. By grounding ourselves in the past, recalling the unexpected twists and turns history has previously taken, we can better navigate the dark of the future.

Solnit's commentary on shadow and light, history and the future, may suggest a different reading of common narratives, both old and new, through which we seek to understand the present moment. On this account, the darkness of the future-not a sinister gloom but the hiddenness of generative uncertainty and possibility - contrasts with the daylight of the present and the past. It is this daylight, she insists, that is carried forward into the dark of the future. It is this light that illuminates the faces of people falling together in the joy-bearing grief-the penthos-of crisis. Our anchoring in the past-its surprises as well as its mistakes-illuminates an uncertain path, and creates a sense of purpose in the present moment. Maybe, then, the Orphean myth gets it wrong. To advance, to move forward, is not to transition in linear fashion from darkness to light. Perhaps the past is not a trap but a repository of memory and insight that can provide stable footing in times of uncertainty and loss. Danger lies not in looking back, but in believing that release from a shadowy past can and should be granted through perpetual, but often "false," forms of motion. The story of the funerary procession on Okjökull, on the other hand, seems to get something fundamentally right, despite the admonition against looking back - a message, perhaps, about being present while confronting the future as the difficult work of grief. A mother's story of moving forward, her hand reaching tentatively behind her, seeking connection with the person in her wake-a person who may or may not be her own child, who may or may not accept the extended hand-this story seems an improvement on the myths we have inherited. The narrative's commingling of grief, hope, solemn action, and sudden unexpected joy is more powerful than "Age of Human" stories of techno-optimism and their disavowal of death, memory, and solidarity. And just as hope, tethered to the past, makes forward motion imaginable, so the young daughter who grasps her mother's outstretched hand embodies what the future may yet become, in all its veiled possibility.

Funding: This research received no external funding.

Conflicts of Interest: The author declares no conflict of interest.

\section{References}

Ackerman, Diane. 2015. The Human Age: The World Shaped by Us. New York: Norton and Company.

Allison, Elizabeth A. 2015. The Spiritual Significance of Glaciers in an Age of Climate Change. Wiley Interdisciplinary Reviews: Climate Change 6: 493-508. [CrossRef]

Bradbrook, Gail. 2019. How Psychedelics Helped to Shape Extinction Rebellion. Insight. March 25. Available online: https://www.whatisemerging.com/opinions/psychedelics-and-social-change (accessed on 5 May 2020).

Brand, Stewart. 2013. The Dawn of De-Extinction: Are You Ready? TED: Ideas Worth Spreading. Available online: https://www.ted.com/talks/stewart_brand_the_dawn_of_de_extinction_are_you_ready/transcript? language $=$ en (accessed on 5 May 2020).

Christie, Douglas E. 2013. The Blue Sapphire of the Mind: Notes for a Contemplative Ecology. New York: Oxford University Press.

Cunsolo, Ashlee. 2017. Climate Change as the Work of Mourning. In Mourning Nature: Hope at the Heart of Ecological Loss and Grief. Edited by Ashlee Cunsolo and Karen Landman. Montreal and Kingston: McGill-Queens University Press.

Farrell, Clare, Allison Green, Sam Knights, and William Skeaping. 2019. This is Not a Drill. New York: Penguin. Hamilton, Edith. 1942. Mythology. Boston: Little, Brown, and Company.

Hance, Jeremy. 2016. Why Don't We Grieve for Extinct Species? The Guardian. November 19. Available online: https://www.theguardian.com/environment/radical-conservation/2016/nov/19/extinctionremembrance-day-theatre-ritual-thylacine-grief (accessed on 5 May 2020).

Heise, Ursula. 2016. Imagining Extinction: The Cultural Meanings of Endangered Species. Chicago: University of Chicago Press. 
Howe, Cymene, and Dominic Boyer. 2019. Cultures of Energy Podcast. Episode 191. August 22. Available online: http://culturesofenergy.com/191-amanda-boetzkes/ (accessed on 10 June 2020).

Jackson, M. 2019. The Secret Life of Glaciers. Brattleboro: Green Writers Press.

Jamail, Dahr. 2019. The End of Ice: Bearing Witness and Finding Meaning in the Path of Climate Disruption. New York: The New Press.

Jenkins, Willis. n.d. Loving Swarms: Religious Ethics Amidst Mass Extinctions. Draft paper.

Johnson, Lacy M. 2019. How to Mourn a Glacier. New Yorker Magazine. October 20. Available online: https://www.newyorker.com/news/dispatch/how-to-mourn-a-glacier (accessed on 5 May 2020).

Klein, Ezra. 2019a. Generation Climate Change. Ezra Sits Down with Varshini Prakash of Sunrise Movement. The Ezra Klein Show. July 31. Available online: https://www.vox.com/ezra-klein-show-podcast/2019/7/31/ 20732041/varshini-prakash-sunrise-movement-green-new-deal (accessed on 5 May 2020).

Klein, Ezra. 2019b. Life After Climate Change with David Wallace-Wells. The Ezra Klein Show. March 4. Available online: https://www.stitcher.com/podcast/vox/the-ezra-klein-show/e/59194732 (accessed on 5 May 2020).

Latour, Bruno. 2018. Down to Earth: Politics in the New Climatic Regime. Translated by Catherine Porter. Cambridge: Polity.

Menning, Nancy. 2017. Environmental Mourning and the Religious Imagination. In Mourning Nature: Hope at the Heart of Ecological Loss. Edited by Ashlee Cunsolo and Karen Landman. Montreal and Kingston: McGill-Queens University Press.

Minteer, Ben. 2014. Is It Right to Reverse Extinction? Nature 509: 261. [CrossRef] [PubMed]

Minteer, Ben. 2019. The Fall of the Wild: Extinction, De-Extinction, and the Ethics of Conservation. New York: Columbia University Press.

Neyrat, Frédéric. 2019. The Unconstructable Earth: An Ecology of Separation. New York: Fordham University Press. Parreñas, Juno Salazar. 2018. Decolonizing Extinction: The Work of Care in Orangutan Rehabilitation. Durham: Duke University Press.

Read, Rupert. 2019. Iceland is Mourning a Dead Glacier: How Grieving over Ecological Destruction Can Help Us Face Climate Change. The Conversation. Available online: https://theconversation.com/iceland-is-mourninga-dead-glacier-how-grieving-over-ecological-destruction-can-help-us-face-the-climate-crisis-122071 (accessed on 5 May 2020).

Rich, Nathaniel. 2014. The Mammoth Cometh. New York Times Magazine. February 27. Available online: https://www.nytimes.com/2014/03/02/magazine/the-mammoth-cometh.html (accessed on 5 May 2020).

Rose, Deborah Bird. 2011. Wild Dog Dreaming: Love and Extinction. Charlottesville: University of Virginia Press.

Rushkoff, Douglas. 2019. Survival of the Richest. In This Is Not a Drill: An Extinction Rebellion Handbook. Edited by Clare Farrell, Alison Green, Sam Knights and William Skeaping. New York: Penguin.

Sideris, Lisa H. 2016. Anthropocene Convergences: A Report from the Field. In Whose Anthropocene? Revisiting Dipesh Chakrabarty's 'Four Theses'. Edited by Robert Emmett and Thomas Lekan. RCC Perspectives: Transformations in Environment and Society 2: 89-96.

Skrimshire, Stefan. 2019. Extinction Rebellion and the New Visibility of Religious Protest. Open Democracy. May 12. Available online: https://www.opendemocracy.net/en/transformation/extinction-rebellion-and-newvisibility-religious-protest/ (accessed on 5 May 2020).

Solnit, Rebecca. 2016. Hope in the Dark: Untold Histories, Wild Possibilities. Chicago: Haymarket Books.

Solnit, Rebecca. 2020a. 'The Impossible Has Already Happened': What Coronavirus Can Teach Us About Hope. The Guardian. April 7. Available online: https://www.theguardian.com/world/2020/apr/07/what-coronaviruscan-teach-us-about-hope-rebecca-solnit (accessed on 5 May 2020).

Solnit, Rebecca. 2020b. On Letting Go of Certainty in a Story that Never Ends. The Literary Hub. April 23. Available online: https://ithub.com/rebecca-solnit-life-inside-this-strange-new-fairytale-doesnt-have-to-be-lonely/ (accessed on 5 May 2020).

Swisher, Kara. 2019. 'The Uninhabitable Earth' author David Wallace-Wells says Tech is Failing on Climate Change. Recode Podcasts. April 10. Available online: https:/www.vox.com/podcasts/2019/4/10/18303533/davidwallace-wells-global-warming-climate-change-uninhabitable-earth-book-kara-swisher-podcast (accessed on 5 May 2020).

Tippett, Krista. 2016. Rebecca Solnit: Falling Together. On Being, March 26.

Van Dooren, Thom. 2016. Flight Ways: Life and Loss at the Edge of Extinction. New York: Columbia University Press. First published 2014. 
Van Dooren, Thom, and Deborah Bird Rose. 2017. Keeping Faith with the Dead: Mourning and De-Extinction. Zoologist 38: 375-78. [CrossRef]

Wallace-Wells, David. 2019. The Uninhabitable Earth. New York: Tim Duggan Books.

Watts, Jonathan. 2019. David Wallace-Wells on Climate: 'People Should be Scared-I'm Scared.'. The Guardian, February 3.

Willox, Ashlee Cunsolo. 2012. Climate Change as the Work of Mourning. Ethics and the Environment 17: 137-64. [CrossRef]

(C) 2020 by the author. Licensee MDPI, Basel, Switzerland. This article is an open access article distributed under the terms and conditions of the Creative Commons Attribution (CC BY) license (http://creativecommons.org/licenses/by/4.0/). 